\title{
A case study of reducing the total wasted time for the bus movement of Public Transportation Authority in Cairo

\author{
Mohamed H. Abdelati ${ }^{1}$, Mohamed I. Khalii ${ }^{2}$, K.A. Abdelgawwad ${ }^{3}$, M.Rabie ${ }^{4}$,
}

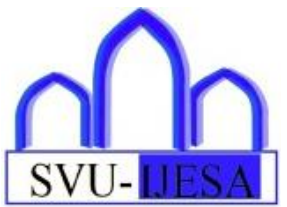

\begin{abstract}
The goal of the transportation model is to improve the time or cost of transportation from the source to the destination.

This paper aims to study the scheduling of the movement of transportation busses for the Public Transport Authority in Cairo, Egypt in the morning from the garages to the departure stations to reduce the time of the transportation trip and thus reduce the cost of the transportation trip.

All the necessary data were collected manually through the busses commuting schedules datasheets in the morning for 30 days and preparation of the transportation model and calculation for minimizing the transportation time have been done using LINGO. The results of this studying reveal that the total waste time of the busses trips can be reduced from 7685 minutes to 5677 minutes by redistribution of the busses trip, which represents about $26 \%$ of the actual times. and saves about $20 \%$ of the amount of fuel consumed per day.
\end{abstract}

Keywords: The initial feasible solution, interactive Fuzzy Multi-objective, Transportation Problem techniques, LINGO.

\section{Introduction}

Received: 28 November 2021/ Accepted: 25 December 2021

$\square$ Corresponding Author,

Mohamed.Rabie, Mohamed.rabie@mu.edu.eg

1. Automotive and Tractors Engineering, Faculty of Engineering., Minia University. Egypt.

2. Egyptian Acadmey for Engineering and Advanced Technology. Egypt

3. Automotive and Tractors Engineering, Faculty of Engineering., Minia University. Egypt.

4. Automotive and Tractors Engineering, Faculty of Engineering., Minia University. Egypt.
It is known that the public transport authority in Cairo, Egypt is very important in daily life. As it is cheap, easily available and covered the wide places in the capital but more careful handling is necessary for the same to ensure that the required services continue to be provided. One of the daily problems faced by the Public Transport Authority is the high operating and maintenance costs of busses. The increase in fuel consumption is one of the most important factors, that lead to an increase in operating costs, due to the long distances traveled, as well as the complexity of the paths through which the bus moves. So in this situation minimizing the distance traveled decreases fuel consumption and consequently decreases the operating costs. In general, the transportation problem helps to determine the transportation cost of any materials from the source to the destination to determine the total number of trips of raw material that comes to a particular source point at a particular period while satisfying supply and demand limits. It is often to estimate the accuracy of transportation cost, delivery time, the quantity of raw materials delivered, demands, availability, the capacity of different modes of transport between sources to destinations this type of problem is frequently called the transportation problem $[1,2]$. The linear programming method is used for determining a way to achieve the best outcome such as maximum profit or lowest cost. However, a given mathematical model for some list of requirements is represented as linear relationships. Linear programming is a specific case of mathematical programming (mathematical optimization) [3]. T.P. has a special nature of linear programming problems [4]. The objective of this problem is to minimize the total transportation cost. The actual T.P. data should be as accurate as possible to achieve a more convenient optimal solution. But in the real-life, it is very difficult to collect accurate data due to the nature of production rates, and the changes in sources availabilities and destinations requirements, and many other reasons [5]. Dealing with inaccurate data is called fuzzy studies, and the transportation problem with fuzzy 
input data is called fuzzy T.P. $[6,7]$.

Minimizing the total transportation cost could not be the only objective for solving transportation problems. T.P can be solved to minimize the total transportation cost, time, distance, deterioration of products, etc... or to maximize the total profit, and more other objectives[8].

\section{Mathematical Model}

The transportation problem is a special kind of Linear Programming Problem (LPP) in which materials are transported from a set of sources to a set of destinations subject to the supply and demand of the sources and destination respectively. The objective of the transportation problem is to determine the cost of the transport from each source to each destination such that the total transportation cost is minimized.

The mathematical formula of the classical transportation problem is described as the following;

Let there be $m$ is the number of sources and $n$ is the number of destinations. Let the amount of supply at the $i^{\text {th }}$ origin is $a_{\mathrm{i}}$. Let the demand at the $\mathrm{j}^{\text {th }}$ destination $b e b_{j}$.

The cost of transporting one unit of an item from source $i$ to destination $\mathrm{j}$ is $\mathrm{c}_{\mathrm{ij}}$ and is known for all combinations $(\mathrm{i}, \mathrm{j})$. Quantity transported from source $\mathrm{i}$ to destination $\mathrm{j}$ be $\mathrm{x}_{\mathrm{ij}}$ (table (1)).

The objective is to determine the quantity $\mathrm{x}_{\mathrm{ij}}$ to be transported overall routes $(\mathrm{i}, \mathrm{j})$ to minimize the total transportation cost. The supply limits at the origins and the demand requirements at the destinations must be satisfied. From the above transportation problem, the total transportation cost " $\mathrm{Z}$ " can be written as the following equation (1):

Min. $Z=\sum_{i=1}^{m} \sum_{j=1}^{n} c_{i j} x_{i j}$

Subject to:

$\sum_{\substack{j=1 \\ n m}}^{n} x_{i j}=a_{i}, \quad i=1,2, \ldots, m$.
$\sum_{i=1}^{n} x_{i j}=b_{j}, \quad j=1,2, \ldots, n$.
$x_{i j} \geq o \forall i$ and $j$.

While the total availabilities are equal to total requirements (i.e. $\sum_{\mathrm{i}=1}^{\mathrm{m}} a_{i}=\sum_{\mathrm{j}=1}^{\mathrm{n}} b_{j}$ ) then the transportation model is called balanced T.P.
Table (1): representation of the classical transportation problem.

\begin{tabular}{|c|c|c|c|c|c|c|}
\hline \multirow{6}{*}{ 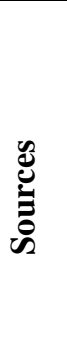 } & \multicolumn{5}{|c|}{ Destinations } & Avai. \\
\hline & $\mathrm{i}$ & $\mathrm{D}_{1}$ & $\mathrm{D}_{2}$ & $\ldots$ & $\mathrm{D}_{\mathrm{n}}$ & $a_{i}$ \\
\hline & $\mathrm{S}_{1}$ & $\mathrm{x}_{11}$ & $\mathrm{x}_{12}$ & $\ldots$ & $\mathrm{x}_{1 \mathrm{n}}$ & $\mathrm{a}_{1}$ \\
\hline & $\mathrm{S}_{2}$ & $\mathrm{x}_{21}$ & $\mathrm{x}_{22}$ & $\ldots$ & $x_{2 n}$ & $a_{2}$ \\
\hline & $\ldots$ & $\ldots$ & $\ldots$ & $\ldots$ & $\ldots$ & $\ldots$ \\
\hline & $\mathrm{S}_{\mathrm{m}}$ & $\mathrm{x}_{\mathrm{m} 1}$ & $\mathrm{x}_{\mathrm{m} 2}$ & $\cdots$ & $\mathrm{x}_{\mathrm{mn}}$ & $a_{m}$ \\
\hline Req. & $b_{j}$ & $\mathrm{~b}_{1}$ & $b_{2}$ & $\ldots$ & $\mathrm{b}_{\mathrm{n}}$ & $\underset{\sum_{\mathrm{i}=1}^{\mathrm{n}=1} b_{j}}{\sum_{j}}=$ \\
\hline
\end{tabular}

\section{About LINGO}

LINGO is the abbreviation of Linear Interactive and General Optimizer, which is an "interactive linear and universal optimization solver". The main purpose of LINGO is to allow a user to quickly input a model formulation, solve it, assess the correctness or appropriateness of the formulation based on the solution, quickly make minor modifications to the formulation, and repeat the process.

LINGO can be used to solve nonlinear programming, and can also be used for solving Linear, Nonlinear, Quadratic, Semi - Definite, Second Order Cone, Integer, and Stochastic optimization models faster, easier, and more efficient. It is a very powerful tool and is the best choice for solving optimization models [9]. LINGO includes a set of built-in solvers to tackle a wide variety of problems. Unlike many modeling packages, all of the LINGO solvers are directly linked to the modeling environment.

This seamless integration allows LINGO to pass the problem to the appropriate solver directly in memory rather than through more sluggish intermediate files $[10,11]$.

An optimization model was creating by LINGO consists of three parts:

Objective function - This is a single formula that describes exactly what the model should optimize.

Variables - These are the quantities that can be changed to produce the optimal value of the objective function.

Constraints - These are formulas that define the limits on the values of the variables.

\section{Case study}

The study was carried out on the busses of the Public Transport Authority in Cairo, which operates in the morning period. The aim is to reduce the non-productive kilometers during the movement when the busses are 
moving from the company garages, where the busses stay to be serviced and maintained, to the starting stations where busses begin their daily journey. The study was applied on the busses of 4 sectors of the company within Cairo, which includes 7 Garages and 22 starting stations.

\section{Methodology}

The study was conducted on the Public Transport Authority in Cairo on 22 start-up stations and 7 major garages. Initially, it was necessary to collect some data from the authority, which can be summarized as follows:

1. The capacity of busses in each garage.

2. The capacity of busses in starting bus stations

3. The distance between each garage and starting stations.

4. The current plan for the distribution of busses on their garages.

After collecting all the previous data, a transportation matrix was created and the total time of the current situation of the Authority's transportation network was found to compare later with the total wasted time after finding the optimal solution to save the wasted time [12, 13]. Table (2) showed the current (actual) distribution of busses.

The distances matrix between each garage and each starting bus station was created, from which the transportation network will be configured for traveling time. Due to the inability to obtain distances between garages and starting stations from the company's data, it has been calculated manually using the Cairo Map and Google Maps. Table (3) illustrates the measured distances between each garage and each starting station in kilometers (Km).

According to CTA data, busses in the morning do not increase the speed of the journey from the garage to the starting bus stations more than $60 \mathrm{~km} / \mathrm{h}$ and not less than $40 \mathrm{~km} / \mathrm{h}$. So, due to lower and higher speeds and stop times at traffic lights and for other reasons, the average speed of the busses was considered to be $50 \mathrm{~km} / \mathrm{hr}$ a fixed speed for all busses.

Based on the distance matrix in Table (3) and the average speed of $50 \mathrm{~km} / \mathrm{hr}$, the time matrix was prepared (time $=$ distance/speed) and constructed in the following table. Table (4) gives the time required for a bus to reach from each garage to each starting bus station in minutes (min).

According to equation (1) and using LINGO software, the optimal distribution of busses trips that minimizes the total transportation time was obtained and tabulated in Table (5).

\section{LINGO Program}

SETS:

SOURCES/G1,G2,G3,G4,G5,G6,G7/:Availabilities; DESTINATIONS/S1,S2,S3,S4,S5,S6,S7,S8,S9,S10,S11,S $12, \mathrm{~S} 13, \mathrm{~S} 14, \mathrm{~S} 15, \mathrm{~S} 16, \mathrm{~S} 17, \mathrm{~S} 18, \mathrm{~S} 19, \mathrm{~S} 20, \mathrm{~S} 21, \mathrm{~S} 22 /:$ Requirem ents;

LINKS(SOURCES,DESTINATIONS):TIME,SHIP; ENDSETS

MIN=@SUM(LINKS:TIME*SHIP); @FOR(DESTINATIONS(J):

@SUM(SOURCES(I):SHIP(I,J))>Requirements(J)); @FOR(SOURCES(I): @SUM(DESTINATIONS(J):SHIP(I,J))<Availabilities(I)) ;

DATA:

Availabilities $=48,126,188,74,124,182,102$;

Requirements $=64,40,10,26,36,28,114,34,20,24,16,25,15,2$ $0,54,52,98,14,32,10,44,68$;

TIME $=20$

$$
17,16,20,19,29,17,19,23,18,22,4,5,10,16,7,11,19,16,2
$$

$0,10,14$,

$14,12,17,22,20,18,10,8,12,8,12,13,16,23,2,10,13,6,10,18,1$ 3,10 ,

$22,18,16,20,16,28,19,22,27,22,24,5,8,16,18,8,2,20,14,19,1$

1,14 ,

$12,7,8,13,12,20,7,11,13,10,13,7,10,17,10,7,8,13,7,13,4,6$, $19,16,13,18,10,27,14,18,20,16,19,11,14,27,17,12,10,22,13$ $, 18,8,12$,

$10,13,18,24,25,10,6,2,4,5,5,20,24,33,7,19,20,7,8,17,17,10$, $7,10,14,19,18,13,5,4,8,4,8,16,18,28,4,14,16,8,5,16,11,7$; ENDDATA

END

\section{Results and discussion}

After solving the previous transportation problem of the Public Transport Authority and finding the optimal solution for it. Noting that the main aim of understudy is to reduce the total time wasted during the movement of busses from garages to service start stations. It was found that the optimal solution is equal to 5677 minutes. Compared to the current distribution and finding the total time for it which was equal 7685 minutes, indicating that it is possible through the new distribution to reduce the total time by $26 \%$ if it is used instead of the current distribution.

This distribution will surely be followed by a reduction in fuel consumption and a decrease in the rates of pollutants and other improvement matters, and by calculating the value of this mitigation. It is also possible to note that annually 12200 hours of wasted time can be saved during this period. 


\section{Conclusions}

The present case study was done on a part of the public transport authority in the capital. The aims of this paper are the study of the current distribution of the busses daily journey from 7 garages to 22 starting stations to reduce bus travel time by redistribution of the busses trips. Redistribution of these busses journey from garages to starting stations it would minimize the time of transporting as well as minimize the consumption of fuel.

LINGO software is one of the best tools to solve transportation problem case studies. Therefore, LINGO software was used to solve the transportation problem using the linear programming method to obtain the optimal distribution of the busses journey.

The total waste time of the actual distribution was 7685 minutes. The total waste time of the optimal distribution is 5677 minutes. The generated optimal solution could reduce a total of 2008 minutes, which represents about 26 $\%$ of the actual times. That is means, about $20 \%$ of the amount of fuel consumed per day can be saved. The new distribution of buses helps to save buses operating time and thus reduce the cost of maintenance, which helps to continue providing good service to the community

\section{References}

[1] H. A. Taha, Operations research: an introduction: Macmillan, 1992.

[2] Dharmendra Yadav and Saurabh Kumar "A Case Study on the Optimization of the Transportation Cost for Raipur steel and thermal power plant," (IJRASET), ISSN: 2321-9653, Volume 5 Issue IX, September 2017

[3] Zavitsas, Kaparias, K. I., M.G.H \& Bell, " Transport problems in cities," $7^{\text {th }}$ Framework Programmer, (Imperial College London). 2010.

[4] A. Omerovic, J. Jusufovic, and M. Can, Optimization of Transport Problems with Fuzzy Coefficients vol. 1, 2012.

[5] J. AlRajhi, K. Alkhulaifi, H. A. Abdelwali, M. AlArdhi, and E. E. Ellaimony, "An Algorithm for Solving Bi-criteria Large Scale Transshipment Problems," Global Journal of Research In Engineering, 2014.

[6] H. Shams, M. D. Mogouee, F. Jamali, and A. Haji, "A Survey on Fuzzy Linear Programming," American Journal of Scientific Research, vol. 75, pp. 117-133, 2012.

[7] W. F. Abd El-Wahed and S. M. Lee, "Interactive fuzzy goal programming for multi-objective transportation problems," Omega, vol. 34, pp. 158-166, 2006.

[8] M. H. Abdelati, M. I. Khalil, K. A. Abdelgawwad, and M. Rabie, "Alternative AlgorithmsL for Solving Classical Transportion Problems," Journal of Advanced Engineering Trends, vol. 39, pp. 13-24, 2020.

[9] Anand Jayakumar, and Raghunayagan, " Solving a Simple Transportation Problem Using LINGO, "International Journal of Innovative Science, Engineering \& Technology, Vol. 5 Issue 4, April 2018

[10] C.Krishnaraj, A.Anand Jayakumar, S.Deepa Shri " Solving Supply Chain Network Optimization Models Using LINGO" International Journal of Applied Engineering
Research ISSN 0973-4562 Volume 10, Number 19 -2015

[11] N. Balaji, and A.N.Balaji " Solving the multi-period fixed cost transportation problem using LINGO solver " International Journal of Pure and Applied Mathematics, Volume 119 No. 12 - 2018.

[12] T. Scales, "Linear Programming: Foundations and Extensions,", Palgrave Macmillan LTD Brunel RD Bldg, Houndmill, Basingstoke, RG21 6XS ..., 2009.

[13] S. Mishra, "Solving Transportation Problem by Various Methods and Their Comparison," International Journal of Mathematics Trends and Technology (IJMTT), vol. 44, p. 6, 4 April2017 2017. 
Table (2) Current (actual) distribution of busses.

\begin{tabular}{|l|l|l|l|l|l|l|l|l|l|l|l|l|l|l|l|l|l|l|l|l|l|l|l|}
\hline & S1 & S2 & S3 & S4 & S5 & S6 & S7 & S8 & S9 & S10 & S11 & S12 & S13 & S14 & S15 & S16 & S17 & S18 & S19 & S20 & S21 & S22 & $\mathbf{a}_{\mathbf{i}}$ \\
\hline G1 & & & & & & & & & & & & 16 & 5 & 20 & & & & & & & 7 & & 48 \\
\hline G2 & & & & & & & 40 & & & & & & & & 50 & 24 & & & 12 & & & & 126 \\
\hline G3 & & & & 21 & & 19 & & & & 24 & 16 & & 10 & & & 23 & 75 & & & & & & 188 \\
\hline G4 & & & & & & & & & & & 9 & & & & 17 & & & & & 37 & 16 & 79 \\
\hline G5 & & 27 & 10 & 5 & 36 & 9 & 14 & & & & & & & & & & 23 & & & & & & 124 \\
\hline G6 & 43 & & & & & & 43 & 26 & 20 & & & & & & 4 & & & 14 & & & & 39 & 189 \\
\hline G7 & 21 & 13 & & & & & 17 & 8 & & & & & & & & & & & 20 & 10 & & 13 & 102 \\
\hline $\mathbf{b}_{\mathbf{j}}$ & 64 & 40 & 10 & 26 & 36 & 28 & 114 & 34 & 20 & 24 & 16 & 25 & 15 & 20 & 54 & 64 & 98 & 14 & 32 & 10 & 44 & 68 & \\
\hline
\end{tabular}

Table (3) Distances between each garage and each starting bus station (Km).

\begin{tabular}{|l|c|c|c|c|c|c|c|c|c|c|c|c|c|c|c|c|c|c|c|c|c|c|}
\hline & S1 & S2 & S3 & S4 & S5 & S6 & S7 & S8 & S9 & S10 & S11 & S12 & S13 & S14 & S15 & S16 & S17 & S18 & S19 & S20 & S21 & S22 \\
\hline G1 & 17 & 14 & 13 & 17 & 16 & 24 & 14 & 16 & 19 & 15 & 18 & 3 & 4 & 8 & 13 & 6 & 9 & 16 & 13 & 17 & 8 & 12 \\
\hline G2 & 12 & 10 & 14 & 18 & 17 & 15 & 8 & 7 & 10 & 7 & 10 & 11 & 13 & 19 & 2 & 8 & 11 & 5 & 8 & 15 & 11 & 8 \\
\hline G3 & 18 & 15 & 13 & 17 & 13 & 23 & 16 & 18 & 22 & 18 & 20 & 4 & 7 & 13 & 15 & 7 & 2 & 17 & 12 & 16 & 9 & 12 \\
\hline G4 & 10 & 6 & 7 & 11 & 10 & 17 & 6 & 9 & 11 & 8 & 11 & 6 & 8 & 14 & 8 & 6 & 7 & 11 & 6 & 11 & 3 & 5 \\
\hline G5 & 16 & 13 & 11 & 15 & 8 & 22 & 12 & 15 & 17 & 13 & 16 & 9 & 12 & 22 & 14 & 10 & 8 & 18 & 11 & 15 & 7 & 10 \\
\hline G6 & 8 & 11 & 15 & 20 & 21 & 8 & 5 & 2 & 3 & 4 & 4 & 17 & 20 & 27 & 6 & 16 & 17 & 6 & 7 & 14 & 14 & 8 \\
\hline G7 & 6 & 8 & 12 & 16 & 15 & 11 & 4 & 3 & 7 & 3 & 7 & 13 & 15 & 23 & 3 & 12 & 13 & 7 & 4 & 13 & 9 & 6 \\
\hline
\end{tabular}


Table (4) Time required to reach the bus from each garage to each service start station.

\begin{tabular}{|l|l|l|l|l|l|l|l|l|l|l|l|l|l|l|l|l|l|l|l|l|l|l|}
\hline & S1 & S2 & S3 & S4 & S5 & S6 & S7 & S8 & S9 & S10 & S11 & S12 & S13 & S14 & S15 & S16 & S17 & S18 & S19 & S20 & S21 & S22 \\
\hline G1 & 20 & 17 & 16 & 20 & 19 & 29 & 17 & 19 & 23 & 18 & 22 & 4 & 5 & 10 & 16 & 7 & 11 & 19 & 16 & 20 & 10 & 14 \\
\hline G2 & 14 & 12 & 17 & 22 & 20 & 18 & 10 & 8 & 12 & 8 & 12 & 13 & 16 & 23 & 2 & 10 & 13 & 6 & 10 & 18 & 13 & 10 \\
\hline G3 & 22 & 18 & 16 & 20 & 16 & 28 & 19 & 22 & 27 & 22 & 24 & 5 & 8 & 16 & 18 & 8 & 2 & 20 & 14 & 19 & 11 & 14 \\
\hline G4 & 12 & 7 & 8 & 13 & 12 & 20 & 7 & 11 & 13 & 10 & 13 & 7 & 10 & 17 & 10 & 7 & 8 & 13 & 7 & 13 & 4 & 6 \\
\hline G5 & 19 & 16 & 13 & 18 & 10 & 27 & 14 & 18 & 20 & 16 & 19 & 11 & 14 & 27 & 17 & 12 & 10 & 22 & 13 & 18 & 8 & 12 \\
\hline G6 & 10 & 13 & 18 & 24 & 25 & 10 & 6 & 2 & 4 & 5 & 5 & 20 & 24 & 33 & 7 & 19 & 20 & 7 & 8 & 17 & 17 & 10 \\
\hline G7 & 7 & 10 & 14 & 19 & 18 & 13 & 5 & 4 & 8 & 4 & 8 & 16 & 18 & 28 & 4 & 14 & 16 & 8 & 5 & 16 & 11 & 7 \\
\hline
\end{tabular}

Table (5) Solution for optimal time.

\begin{tabular}{|l|l|l|l|l|l|l|l|l|l|l|l|l|l|l|l|l|l|l|l|l|l|l|l|}
\hline & S1 & S2 & S3 & S4 & S5 & S6 & S7 & S8 & S9 & S10 & S11 & S12 & S13 & S14 & S15 & S16 & S17 & S18 & S19 & S20 & S21 & S22 & ai \\
\hline G1 & & & & & & & & & & & & 13 & 15 & 20 & & & & & & & & & $\mathbf{4 8}$ \\
\hline G2 & & & & & & & & & & 24 & & & & & 54 & & & 14 & 24 & & & 10 & $\mathbf{1 2 6}$ \\
\hline G3 & & & & 16 & & & & & & & & 12 & & & & 52 & 98 & & & 10 & & & $\mathbf{1 8 8}$ \\
\hline G4 & & 40 & & & & & & & & & & & & & & & & & & & & 34 & $\mathbf{7 4}$ \\
\hline G5 & & & 10 & 10 & 36 & & & & & & & & & & & & & & & & 44 & 24 & $\mathbf{1 2 4}$ \\
\hline G6 & & & & & & 28 & 84 & 34 & 20 & & 16 & & & & & & & & & & & & $\mathbf{1 8 2}$ \\
\hline G7 & 64 & & & & & & 30 & & & & & & & & & & & & 8 & & & & $\mathbf{1 0 2}$ \\
\hline bj & 64 & 40 & 10 & 26 & 36 & 28 & 114 & 34 & 20 & 24 & 16 & 25 & 15 & 20 & 54 & 52 & 98 & 14 & 32 & 10 & 44 & 68 & \\
\hline
\end{tabular}

